Rev. ANPOLL, n. 8, p. 103-129, jan./jun. 2000

\title{
REDEIMOINHO ÀS AVESSAS OU UM EU SE AUTO-(RE)CLAMA SUJEITO
}

Luiz C. Borges ${ }^{*}$

RESUMO: A partir dos pressupostos teóricos da Análise do Discurso, o objetivo principal deste trabalho é refletir acerca da noçāo central de sujeito do discurso, compreendendo-o como um dos pilares da formaçāo histórico-ideológica, segundo urna leitura marxista do discurso. Assim, para entender ofuncionamento discursivo do sujeito, bem como sua configuraçāo e constitutividade, é necessário apreendê-lo nos eixos do reconhecimento/identificaçāo, contra-identificação e alteridade. A füm de situar melhor a discussāo, é estabelecida uma relaçāo, de caráter analitico e metodológico, entre o sujeito do inconsciente, considerado pela Psicanálise e o sujeito do discurso. Mediante esse procedimento, puderam ser estabelecidos alguns pontos de convergência e de divergência entre a perspectiva teórica psicanalítica e a marxista, no que tange à constituiçāo e funcionamento discursiuo da noçāo de sujeito.

PALAVRAS-CHAVE: Sujeito; Ideologia; Alienação; Identificaçāo.

\section{Sujeito..., quem?}

A proposta deste trabalho consiste em refletir acerca do 1 problema do sujeito, no interior do quadro teórico-metodológico da Análise do Discurso (daqui para adiante referida como

- Pesquisador Associado do MCT/Museu de Astronomia e Ciências Afins do Rio de Ja-

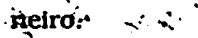


BORGES, Luiz C. Redemoinho às avessas ou um eu se auto-(re)clama sujeito.

$\mathrm{AD})$, e tendo como referência mais abrangente uma teoria geral das ideologias, no interior do Marxismo. O status teórico do problema do sujeito se apresenta, não apenas como condição indispensável para pensar a lingua e o sentido, o que implica imediatamente a questão da discursividade, mas e principalmente, como reflexão indispensável para tratar de uma teoria da ideologia, à luz de um dispositivo conceitual que, simultaneamente, procura comprender o funcionamento geral das sociedades, e construir ferramentas visando a sua transformação.

Isto posto, fica claro que no contexto deste trabalho, o sujeito (e tudo aquilo que dele deriva: subjetividade, assujeitamento, intersubjetividade etc.), só pode ser pensado como parte constitutiva e instituinte da ideologia. Nesta perspectiva, o sujeito constitui uma das noçōes teóricas centrais para a $\mathrm{AD}$ que, porém, não trata o sujeito como um conceito genérico, de tipo ontológico, visto que é como sujeito-do-discurso que este comparece nas análises e reflexões teóricas dessa disciplina. Semelhantemente ao que ocorre na psicanálise, em que o sujeito é definido como sujeito do desejo inconsciente, no dispositivo teórico-metodológico da $\mathrm{AD}$, a palavra sujeito funciona como uma abreviatura.

De acordo com os pressupostos teórico-metodológicos da $\mathrm{AD}, \mathrm{o}$ sujeito manifesta uma dupla determinaçāo (contraditória, dialética), mediante a qual, ao mesmo tempo em que o enunciado, encontra-se constrangido e determinado por sua formação sócio-histórica e, imediatamente, pela ordem discursiva na qual e pela qual se encontra identificado. Isto é, o sujeito inscreve-se na linguagem e simultaneamente na historicidade, o que significa dizer que o sujeito e o sentido do seu dizer determinam-se na e pela história, sendo essa a condição irrecusável para que haja discursividade. A condição radical da relaçāo sujeito-discurso $\Leftrightarrow$ sentido exige que "para que o seu discurso tenha um sentido, é preciso que ele já tenha sentido, isto é, o sujeito se inscreve (e inscreve o seu dizer) em uma formação discursiva que se relaciona com outras formaçōes discursivas" (Orlandi, 1990: 177). 
Para a $\mathrm{AD}$, o sujeito é entendido como descentrado, ou seja, ele nāo é o centro ou a fonte dos sentidos que produz, embora seja integrante do processo de produçāo, cujas determinaçōes são históricosociais. De certo modo, o sujeito encontra-se alienado em relaçāo ao sentido, alienaçāo que é produzida pela ilusāo mesma da transparência do sentido. Isto é, da evidència de sentido pela qual o indivíduo concebe-se como o sujeito de sua história, quando, de fato, encontra-se determinado pelas condições ideológicas de produção/reprodução das relaçōes de produçāo e das relaçōes sociais delas constituidas e contraídas. Assim sendo, o sujeito e o sentido nāo devem ser procurados nas palavras de um individuo ou nas de um texto, mas nas relaçōes com outros textos, outras palavras e outros individuos. Relaçōes nas quais e pelas quais o sentido e o sujeito se constituem enquanto efeito ideológico de um processo histórico-social.

De acordo com o estágio atual das reflexões acerca do sujeito, uma de suas caracteristicas que tem sido ressaltada refere-se à alienaçāo (opacidade do processo de assujeitamento, esquecimento constitutivo) como elemento instituinte da subjetivaçāo. Emprego o termo subjetivação em lugar de subjetividade, uma vez que esta diz respeito aos processos de construção da forma-sujeito (sua historicidade), ao passo que a subjetividade, - significando o que é próprio do sujeito, concebido tradicionalmente, no campo geral do idealismo e suas múltiplas facetas, como uma categoria ontológica e socialmente autônoma - remete a uma concepçāo do sujeito como ser auto-consciente, coincidente consigo mesmo e, como tal, senhor (via razāo consciente do conhecimento e da intencionalidade) do seu dizer e dos sentidos. É esta concepção do sujeito como um ente-em-si, completo, que se liga a outras consciências igualmente autônomas, através de acordos comunicativos e/ou interação societária, que pode ser sintetizada pela expressão sedução da subjetividade.

Conceber o sujeito nesses parâmetros significa construir um contra-senso, quer à luz da $\mathrm{AD}$, quer segundo o materialismo histórico, dado que a subjetividade, entendida como um em-si, reduz-se, 
BORGES, Luiz C. Redemoinho às avessas ou um eu se auto-(re)clama sujeito.

quando retirados os véus ideológicos que a sustentam, a uma forma ideológica, necessariamente alienada, do processo de subjetivação levado a cabo pelos Aparelhos Ideológicos da Sociedade (AIS). Nestes termos, a subjetividade constitui-se em um lugar onde operam os mecanismos de validação psicológica próprios dos AIS.

Considerando o processo de instituiçāo/atuaçāo do sujeito, na teoria lacaniana do inconsciente trabalha a noção de véu de alienação (Leite, 1994), que condena o sujeito a estar no entremeio da perda, visto que a "alienação ao significante é constitutiva do sujeito, (...), imposta como o preço por ser falante" (Leite, op. cit.: 41). Enfocado nesta perspectiva, deriva do processo mesmo de subjetivação o desconhecimento estruturante, a alienaçāo, de que o sujeito é portador. $E$, uma vez que o sujeito encontra-se envolto pelo véu da alienaçāo, ele é também afetado pela ilusāo da subjetividade que o faz tomar-se por causa, quando ele é, de fato, efeito.

Para Badiou (1994), o sujeito é uma ocorrência local no processo de verdade. $\mathrm{O}$ sujeito é, entāo, um ponto ou um efeito de verdade, e de modo algum configura-se como uma origem. Sendo constituído e construido pelo sentido, é evidente que o sujeito não pode ser, por sua vez, a fonte do sentido, visto que a condição sujeito (a formasujeito) depende das condições histórico-sociais para se manifestar. É porque existe o processo de constituição dos sentidos que o sujeito existe. Assim, compreende-se que sujeito e sentido sejam simultânea e mutuamente constituidos pelos processos históricos, de modo que o sujeito representa-se como uma formação local de um processo sócio-histórico de construçāo de pontos cristalizados de verdade.

Para referir ao fato de que o sujeito porta a ilusão de que ele se encontra na origem do dizer e do sentido, e de que ele toma por real o que, na verdade, é representação, Pêcheux propōe o estabelecimento de duas categorias de esquecimento (Leite, 1994; Pêcheux, 1988; Pêcheux \& Fuchs, 1990). No primeiro caso, ressalta-se a relação entre o sujeito e a lingua; no segundo, a relação entre linguagem, pensamento e realidade. Em ambos os casos, a ilusão subjetiva, instituinte 
da incompletude do sujeito, como efeito dos processos ideológicos, afeta a discursividade.

As categorias de esquecimento propostas por Pêcheux trazem à discussão a noção de alienação, a qual deve ser entendida como uma forma de esquecimento instituinte ou fundante. A alienação representa a contradiçāo radical entre os homens e sua realidade. Vale dizer, aos mecanismos de assujeitamento que fazem de cada individuo um sujeito-massa.

Há uma critica em relaçāo ao conceito de alienação, segundo a qual este termo portaria uma implicação lógica que pressupōe um momento histórico em que se processaria uma desalienaçāo. Contudo, se se considera que para o sujeito é impossivel encontrar-se fora da ideologia - e é preciso recordar que o conceito de alienação deriva do fato de haver ideologia -, pois o fora da ideologia é apenas um efeito de ilusāo produzido por uma (outra) ideologia; e se o não-sentido não significa, de fato, uma negaçāo ou anulação do sentido, mas apenas uma de suas instâncias, então posso dizer que a desalienação é apenas um deslizamento parafrástico no labirinto da alienação.

A alienaçāo, por outro lado, não se opōe à conscientização, nem tampouco à ausência de participaçāo sócio-politica, visto que a tomada de consciência não "liberta" o sujeito de sua "alienação social". Dai que a alienação não pode colocar-se como sinônimo de "falta de consciência", ou de alheamento. Trata-se, em suma, de um processo estruturante próprio do atravessamento ideológico instituinte das formações sociais. Alienação è, pois, ruptura. Em cada um das instâncias da vida histórico-social manifesta-se um tipo ou um nivel de alienação. Assim entendida, pode-se dizer com Codo (1986: 70, 77) que a "alienaçāo é ser e não ser ao mesmo tempo", e que ela "gera consciência, que gera alienação, que gera consciência..."

Deste modo, a alienação se configura como um despertencerse, um estar em irremediável disjunção entre o eu e o sujeito, e entre estes e a ordem simbólico-imaginária e a formaçāo histórico-ideológica do mundo, de forma que a alienação implica na construçāo da 
BORGES, Luiz C. Redemoinho às avessas ou um eu se auto-(re)clama sujeito.

falsa consciência como efeito de deslocamento ou defasagem entre o individuo, tornado sujeito, e sua prática social e as relações imaginárias que mantém com o mundo.

Dizer que o sujeito, em sua alienação fundante, é portador de uma falsa consciência nāo significa que se trata de uma consciência falsa, que engane ou que iluda. Trata-se de, considerando que os homens adquirem consciência de si e do mundo no terreno da ideologia, compreender que a sua consciência deriva das formaçōes histórico-ideológicas dominantes. A falsa consciência não é um fenômeno subjetivo, ainda que manifeste efeitos de subjetividade, trata-se, antes, de uma ilusão objetiva constitutiva do processo de assujeitamento, a qual funciona como uma espessura que opacifica o fato de que sāo as condiçōes materiais da existência social que determinam a consciência social e a individual. É um efeito da falsa consciência que permite ao sujeito pensar que è a sua consciência, vontade ou desejo que são a fonte do seu dizer/fazer.

Por este motivo, o termo alienação está sendo assumido com a sua implicação de incompletude constitutiva, como propriedade do sujeito. Da mesma forma que para o sentido, a incompletude do sujeito dá conta do fato de que o sujeito não é absoluto, auto-suficiente, completo. De um lado, a incompletude implica a relaçāo entre o sujeito e a (sua) linguagem, relaçāo mediada pelo imaginário. Ou seja, devido ao fato da nảo-coincidência entre a ordem da lingua e a ordem do mundo, è pela intervenção do imaginário que se configura a interseção entre essas duas ordens. De outro lado, implica o fato de que o sujeito, sendo constituído socialmente, é portador de uma contradição irresolúvel: a de que aquilo que o constitui determina-se de fora, é-lhe exterior, como condição mesma de sua constituição. Em suma. a incompletude, a partir da qual o sujeito se institui, é parte dos processos ideológicos de assujeitamento. Possenti (1990) desenvolve uma instigante análise, com base numa leitura de Althusser, acerca da questāo do sujeito, na $\mathrm{AD}$, especialmente no que se refere à sua determinação na/pela história. Leite (1994) também, à luz da teoria 
psicanalítica, faz uma reflexão tendo como foco a questāo do assujeitamento, via interpelaçāo, e as relaçōes entre o campo discursivo e o psicanalitico.

De qualquer modo, a subjetividade, ao menos na perspectiva discursiva, fundamenta-se e funciona com base em mecanismos lingüisticos especificos, em que participam a ordem do ideológico, a intervenção do imaginário, os processos histórico-sociais que, em suma, determinam a subjetividade, uma vez que os processos de assujeitamento são de natureza histórica (Orlandi, 1987).

Concebido, discursivamente, como resultante de uma determinação histórica, o sujeito nāo comparece como um em-si, mas em forma de posiçōes discursivas (nas quais marca-se o lugar social dos locutores, lugar social que se inscreve no dizer do sujeito), as quais sāo, por sua vez, derivadas das relações, em que intervém o imaginário, entre a lingua e a sociedade. E porque o sujeito resulta de processos históricos de assujeitamento - de maneira que cada formação histórico-social-ideológica produz assujeitamentos diferenciados - "o que temos sāo formas-sujeito" resultantes de "processos de identificação em que joga o esquecimento" (Orlandi, 1994: 302). Ou seja, a forma-sujeito é uma construçāo teórica para dar conta da constituiçāo histórica das formas (e da formação) subjetivas, uma vez que não há um sujeito universal nem atemporal. Segundo Haroche (1992: 200), na concepção de sujeito do discurso incidem os processos discursivos que "contribuem, pelo mecanismo ideológico de reconhecimento e identificaçāo, para descentrar a determinaçāo, colocando-a fora do sujeito". A forma-sujeito é, então, um efeito dos mecanismos ideológicos e, como tal, se define como a forma histórica de existência do individuo determinado por suas relações sociais, sempre mediatizadas pelo jogo de representações que o sujeito constrói em sua interaçāo com a sociedade.

Esquematicamente, o sujeito do discurso pode ser representado da seguinte maneira: 


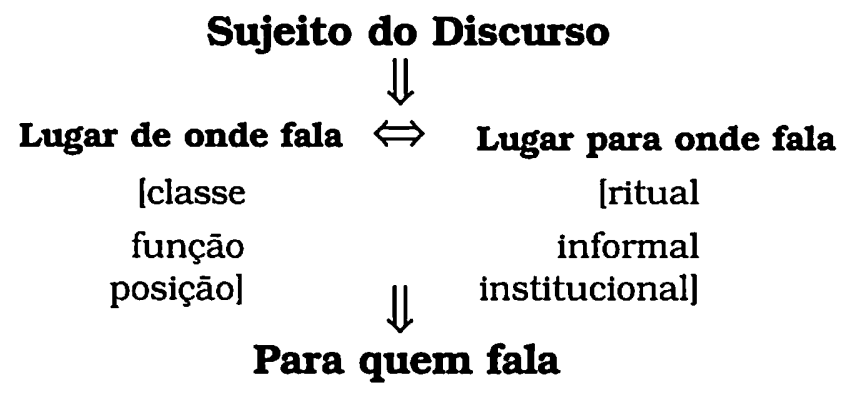

Neste esquema sāo mostradas as relaçōes que o sujeito (do discurso) mantém com a situação histórico-social, objetivamente verificáveis. É igualmente a partir dessas relaçōes que os processos de significação atuam. Desta forma, o sujeito, discursivamente entendido como dividido, descentrado, determinado de fora, manifesta no eu a ilusão necessária de centramento, de unidade, de completude. O eu realiza-se como entidade que, no imaginário instituido do sujeito, constrói a imagem de autonomia (o-sem-precedente), de senhor do seu dizer e dos sentidos ai produzidos. E, deste modo, através da constituição deste eu, manifesta-se o que pode ser denominado de sedução da subjetividade.

A sedução da subjetividade (a ilusão subjetiva) resulta de um movimento de imposição/dissimulação da ideologia. enquanto efeito metonimico (Herbert, 1995): de um lado faz o sujeito identificar-se com as estruturas política e ideológica da qual ele nāo se descola e, de outro, recalca, faz necessariamente esquecer que essa identificação, como consciência de si e da situação, bem como do efeito de evidència de que o sujeito é a origem do seu fazer/dizer, resulta de um processo ideológico pelo qual a sua posiçāo na estrutura encontra-se dissimulado, silenciado por essa mesma evidência da subjetividade. A sedução da subjetividade relaciona-se, outrossim, à representaçāo de uma individualidade soberana, mediante a qual o sujeito crê-se, num espécie de efeito Münchhausen, ser a causa de si mesmo. 
Um ponto que deve ser destacado, no âmbito dos processos de subjetivação/assujeitamento, é o fato de que, entre as instâncias do sujeito e do eu, ocorre uma descontinuidade, de forma que sujeito e eu são dissimétricos - quer sejam considerados à luz da teoria do inconsciente, quer o sejam a da ideologia. Isto significa que é pela instância do eu que o sujeito manifesta a ilusão (o véu da alienação, a falsa consciência, que lhe é institutiva) de que os processos de significaçāo lhe são decorrentes.

A questāo sujeito/eu manifesta relações ideologizadas de nivel abstratizante, de forma a que seja gerada a ilusāo de que é o individuo em sua plena liberdade subjetivizante o responsável pelos processos históricos de significação (alienação produtora da ilusão de subjetividade). As instâncias pelas quais o ser social se manifesta, sujeito-eu-individuo, podem ser entendidas como niveis diferenciados de uma mesma categoria: a forma-sujeito cuja definiçāo é histórico-ideológica. Em vista disso, o que se tem é:

$\Rightarrow$ Sujeito: nivel teórico. Definição histórico-ideológica. Posição discursiva (enunciação)

$\Rightarrow E u$ : nivel analitico. Definição histórico-psico-social. Realização lingüistica (enunciado)

$\Rightarrow$ Individuo: nivel analitico. Definição bio-psico-social. Agente da vida social (acontecimentos).

Desta forma, o sujeito se materializa lingüisticamente no eu, o qual, por sua vez, se especifica no individuo. $O$ eu é a materialidade histórico-social do sujeito, e o individuo è a materialidade bio-psicosocial do eu. Uma outra forma de mostrar as relaçōes entre essas três instâncias é dizer que o individuo atua na sociedade em sua forma enunciada de eu (ilusão da subjetividade), mas é como (forma)sujeito que ele intervém na história. Assim sendo, o sujeito manifesta no eu a ilusão da evidência de que existe fatualmente a presença de uma vontade, psiqué, que a tudo ordena e comanda (sedução da subjetividade). 
BORGES, Luiz C. Redemoinho às avessas ou um eu sø auto-(re)clama sujeito.

O desenvolvimento do eu processa-se na relação contraditória entre os impulsos de cada individuo, como unidade bio-físio-sóciopsicológica, e a coerção produzida pela determinação e representaçāo sociais, qual seja, pela formaçāo histórico-ideológica da sociedade. Trata-se de uma cadeia complexa de estruturas complexas determinando e sendo determinadas por outras estruturas igualmente complexas: sobredeterminacão. Deve-se, pois, considerar ainda, nesse processo de construção do eu, o papel do grupos sociais, os quais funcionam como instâncias de transmissão e manutenção das formas ideológicas dominantes. Ao mesmo tempo em que preparam a cena em que se representa o sujeito do discurso.

A disjunção operativa no nivel sujeito/eu também opera em relaçāo às categorias sujeito discursivo/sujeito lingüistico (no jogo das instâncias fundadoras, o discurso funda o sujeito; a lingua, o eu - realizado no/pelo individuo). Ou ainda, entre locutor (aquele que é responsável pelo enunciado, ainda que não seja necessariamente o produtor deste enunciado) e enunciador (cuja voz, mesmo que corporificada na enunciação, não pode, entretanto, ser individualizada).

Uma vez que a relaçāo disjuntiva sujeito/eu só pode ser, efetivamente, compreendida a partir dos processos de determinação/alienação ideológica, apresento, abaixo, alguns traços que, esquematicamente, caracterizam cada um dos membros da relação.

\begin{tabular}{|l|l|}
\hline \multicolumn{2}{|c|}{ IDEOLOGIA } \\
\hline Individuo & Sujeito \\
\hline Eu & Forma-sujeito \\
\hline lugar da fuga & lugar do assujeitamento \\
\hline lugar da não-dispersão & lugar da incompletude \\
\hline lugar da ruptura & lugar da ilusão subjetiva \\
\hline lugar da transparência & lugar da opacidade \\
\hline centramento & des-centramento \\
\hline interioridade & Exterioridade \\
\hline autonomia & Determinação \\
\hline
\end{tabular}


Partindo desses traços que constituem o individuo (o lugar do eu) e o sujeito, é possivel estabelecer um paralelo com o sentido, no que respeita a relação entre a transparência e a opacidade. Assim como, no jogo dos sentidos, se manifesta um efeito de transparência. pelos mecanismos discursivos, que provoca no locutor a ilusão de que è dele que o sentido emana; transparência que, por sua vez, desfoca o fato de que há uma opacidade que permanece irreconhecida pelo sujeito; assim também, o eu assume-se como transparente (autônomo, livre) para o individuo, e este efeito, por seu turno, o aliena dos processos de assujeitamento. Esta condição de sujeito permite dizer com Henry (1990) que, dado que o exterior de uma ideologia é o interior de uma outra ideologia, o sujeito pode ser analisado como e enquanto um efeito ideológico elementar.

$\mathrm{Na} A D$, trabalha-se com a noção de opacidade estruturante, a qual se refere à impossibilidade radical - dadas as condições do processo de assujeitamento e da formaçāo histórico-ideológica - de haver, por parte do sujeito, um atravessamento ideológico que o permita vislumbrar a rede de condicionamentos a qual encontra-se filiado. Desse modo, falar em opacidade constitutiva dos processos de assujeitamento e de significaçāo significa afirmar que o sujeito não controla livremente o seu dizer.

Se o sujeito fosse livre para significar o seu dizer, isso implicaria em ter de admitir a anterioridade do sujeito à ordem da significaçāo. Se assim fosse, ter-se-ia de admitir que o imaginário, o simbólico e o ideológico, em seu papel de forças materiais da história, estariam sendo produzidos a partir do sujeito. Tal, entretanto, nāo è o que ocorre, pois o sujeito encontra-se, sempre e inexoravelmente, imerso na ordem do ideológico.

No dizer do sujeito atuam outros dizeres, forças histórico-sociais que independem de sua vontade e/ou intencionalidade, visto que essa vontade-intencionalidade pode ser compreendida como a emergência da consciência, do Eu. Ora, se no sujeito estāo sempre atuando constitutivamente forças que escapam de sua vontade sub- 
BORGES, Luiz C. Redemoinho às avessas ou um eu se auto-(re)clama sujeito.

jetiva, então a intencionalidade revela-se um componente do jogo de ilusão que, de fato, constitui a consciência do sujeito, visto que essa se apresenta como "efeitos de evidência produzidos pelos mecanismos ideológicos" (Orlandi, 1992:16).

Dizer que o sujeito é constituido pela ação de mecanismos ideológicos não significa afimar que o sujeito seja reduzido a mero autômato social. Nāo se pode esquecer que, pela instância do $\mathrm{Eu}$, o sujeito detém um controle relativo do seu dizer. O que fica ressaltado desse complexo de sobredeterminaçōes, é que há um jogo complexo determinador da ilusão da autonomia subjetiva, pelo qual se atribui um papel de agente da história ao sujeito, ao mesmo tempo em que apaga nele a determinaçāo do complexo de condições referentes às estruturas histórico-sociais nas quais se encontra imerso.

\section{Ilusão do sujeito; sujeito da ilusão}

Angel Heart, personagem central do filme Coraçāo Satânico, de Alan Parker, é um detetive: um descobridor de pistas: um rastreador: um decifrador de sinais/enigmas. Contratado por um cliente misterioso, Louis Sypher (sypher = cipher: cifra, escrita cifrada ou secreta, criptograma (nome oculto) - nome que, pronunciado, torna-se LUCIFER: o nome oculto/revelado no nome-vestimenta: o nome por detrás da máscara do nome; nome que demanda estar na ordem do sentido, no movimento mesmo do silêncio censório que o interdita - para descobrir o paradeiro de um terceiro personagem, desaparecido, devedor de uma divida jamais paga ao contratante. Forma-se, então, um triângulo: o que contrata, o que busca e o procurado/oculto. A procura é labirintica/circular. Há pistas, mas essas pistas deslocam, afastam e. à medida que o detetive as junta, o círculo vai inexoravelmente fechando-se em torno do buscador. Ainda assim, o decifrador se desloca, recusando-se e recusando-as, tal qual Édipo que foge do vaticinado tão-só para descobrir-se no coração de sua plena realização. 
Angel Heart busca uma identidade que lhe está encoberta e presente: na sua busca e em seu nome e nas pistas que vai recolhendo. Mas há nele uma resistência que o desvia para outros magmas de significaçāo. Embora ele saiba a quem busca, recusa-se a admitir já ter encontrado. Assim, quando o circulo da busca se fecha definitivamente e há uma verdade que lhe é imposta, sua reaçāo, de desespero, é ainda de resistência. Ele clama por uma identidade que (n)ele se evidencia. Recusa a identidade, também sua, prévia e substrato daquela com a qual ele se opacifica, satura-se no excesso e no silenciamento. Recusa a divida que lhe é cobrada (a ironia do filme assemelha-se à ironia do mito edipiano). Angel Heart defende-se, apega-se a uma identidade que lhe convém, afirmando: eu sei quem eu sou!

O que está em pauta, no resumo acima do filme, é o confronto/ contradiçāo/conflito estabelecido entre um eu afirmado e um sujeito reclamado. Em Angel Heart, eu e sujeito não coincidem, são desajustados, excêntricos, como de resto, aliás, em todos os personagens reais. E esse é um ponto crucial caracteristico da relaçāo entre o eu que enuncia e um sujeito que é enunciado.

Há, ainda uma outra vertente pela qual a (des)coincidência do sujeito consigo mesmo - aliás, a condição mesma que define o indivíduo como sujeito -, pela instância do eu, manifesta-se. Des-coincidência que se materializa na linguagem sob a forma de dêiticos discursivos do tipo EU-AgUI-AGORA (Pêcheux, 1988), os quais apontam para a evidência de que o sujeito, afetado pela sedução da subjetividade que lhe é instituinte, representa-se como encontrando-se em plena posse do reconhecimento de seu lugar e da sua condição. Trata-se da contra-identificação (ou da contra-identidade) de que fala Pêcheux (1988), pela qual o sujeito recusa identificar-se com a formaçāo histórico-ideológica que o condiciona, bem como os papéis que lhe são determinados, atribuindo-se, por outro lado, uma outra filiação interdiscursiva e produzindo o discurso-contra.

Considerando o esquema dêitico exposto acima, é possivel supor que, na contra-identificaçāo (que, por sua vez, caracteriza o "mau" 
BORGES, Luiz C. Redemoinho às avessas ou um eu se auto-(re)clama sujeito.

sujeito), esse esquema funcione com os sinais negativos: NãoEUNãoAQUI-NãoAGORA, e pode ser demonstrado pelo seguinte enunciado: "eu não sou eu". Neste tipo de enunciado, o sujeito recusa uma identidade que lhe é atribuida como determinaçāo exterior. Esta situação discursiva pode ser parafraseada da seguinte forma: "'você é x'; 'eu não sou x", onde a segunda ocorrência de eu do enunciado contra-identificador, que é negado $(e u \neq e u)$, equivale a "eu nāo sou o $x$ (que você diz que eu sou)".

Nos dois casos em pauta, ocorre uma identificação equivocada. No caso de Angel Heart, trata-se de um auto-equivoco, diante do qual a declaraçāo "eu sei quem eu sou" funciona como uma recusa frente às evidências que a desconstrução (no processo de busca pelo fugitivo, que se desenrola de pista em pista) expōe-lhe inexorável: ele é quem ele [sem o saber] busca. Diante dessa constataçāo de que ele, na verdade, não é quem ele pensa [que sabel quem é, mas esse outro recalcado, dissimulado em outra máscara-eu, vem o repúdio, a terminante recusa em aceitar-se sendo este outro denegado e, em certo sentido, opacificado pela amnésia da (nova) consciência ou personalidade com a qual ele até então se identificava.

E contudo, esse outro recalcado retorna, expõe-se integralmente. E o grito desesperado de recusa representa uma declaraçāo da impotência diante do verdadeiro eu que lhe é desvendado (e a narrativa do filme expōe, em forma de imagens-resumo do passado, os episódios que antes, porque recalcados pela personagem, não foram mostrados e que funcionam, pelo não-dito, como reveladores da identidade criptica de Angel Heart).

No segundo caso, a identificação equivocada trabalha em outro espaço de reconhecimento. Não se trata de um auto-equivoco, sobre o qual atua um proceso de auto alienação/desconstrução, porém de um exo-equivoco provocando uma falsa identificação. É o caso de alguém que, tendo sido confundido com outrem, ao afirmar sua identidade, descola-se da que lhe é atribuida. O sentido do enunciado "eu não sou eu", parafraseado como "eu não sou este eu com o qual me 
identificam", aponta para a ocorrência de um processo de dispersāo de identidade. Ainda que, ironicamente, o seu efeito de perturbaçāo no sistema de reconhecimento-identificação-atribuição tenha a virtude de pôr a nu o fato de que a) eu e sujeito nāo coincidem; b) o sujeito, por definição, descoincide consigo mesmo, ou seja, o sujeito institui-se constitutivamente heterogêneo em uma homogeneidade imaginária.

No entanto, do ponto de vista da sobredeterminaçāo ideológica, é lógico pensar que tanto a identificaçāo quanto a contra-identificaçāo pertençam ao mesmo espaço discursivo da forma-sujeito. É o que Pêcheux (op. cit.: 216) afirma ao dizer que "o interdiscurso continua a determinar a identificação ou a contra-identificação do sujeito com uma formaçāo discursiva, na qual a evidência do sentido lhe é fornecida, para que ele se ligue a ela ou que a rejeite". $E$ isto leva a considerar que, tendo em vista o trabalho dos aparelhos ideológicos de sociedade, para romper com o interdiscurso vigente è preciso ir além da dicotomia identificaçāo/contra-identificaçāo.

À dialética eu/sujeito corresponde um desejo de identificaçāo: seja porque um individuo imagina-se desta ou daquela maneira (como se estivesse diante de um espelho), seja porque nele opera um desejo de identificação: há um ideal com que identificar-se, o qual é determinado pelo interdiscurso e pelo pré-construido. A primeira atitude representa uma identificação especular, a segunda uma identificação simbólica, segundo Safouan (1970). Para ele, o eu do enunciado aponta para um fantasma, porque impossivel de se refletir na imagem especular. Neste caso, o sujeito configura um ausente, cuja não-presença é preenchivel simbolicamente. Mas a matéria que preenche o sujeito não pertence ao controle do eu enunciante. Deste modo, ao clamar "eu sei quem eu sou", ou "eu não sou eu", a que sujeito reclama este eu?, com que identificação busca desesperadamente (e talvez, inutilmente) preencher(-se) esse fantasma que deseja evidenciar?

Evidência. Eis outro termo que gira em torno da distância (impreenchivel?) entre eu e sujeito. Ao dizer eu, parece evidente o 
BORGES, Luiz C. Redemoinho às avessas ou um eu se auto-(re)clama sujeito.

que se quer dizer. $O$ sentido ( $=0$ sujeito) do eu parece não requerer maiores reflexões para se anunciar. É auto-evidente. $\mathrm{O}$ eu agarra-se a este sentido "sempre-já dado". Esta é a ilusāo do eu. Como sintese enunciativa das identidades que sintomaticamente se resume numa única máscara.

As evidências são jogos/efeitos ideológicos. É por esse efeito de ilusāo que os sentidos das palavras parecem tão exatos, óbvios. É, ainda, através desse jogo que se estabelecem as verdades, a liberdade de escolha, a imparcialidade, a transparência dos processos, das coisas, das palavras.

Aos sentidos possiveis (flutuantes) do que seja sujeito, há um eu que se adere e os torna visiveis, mesmo que permaneçam subjacentes a um sentido que se cristaliza, no imaginário, como global, auto-evidente, anunciado pela afirmaçāo do eu. O que este eu afirma é uma unidade ideal que, ao ser reivindicada como real, ilusoriamente desfaz a distância entre eu e sujeito, provocando a impressão de que ao eu corresponde direta e imediatamente um único sentido, que é a própria identidade imaginada do locutor. Dito de um outro modo, a afirmaçāo (discursiva) do eu representa um conjunto de sintomas de reconhecimento desse sujeito ideal reivindicado.

Entre o eu e o sujeito permeia um jogo de imagens e fantasias. Neste jogo de máscaras, o sujeito, como efeito ideológico/ideal imaginário, insere-se na cena da ligação identitária em que a fantasia se apresenta. A fantasia de origem do eu encontra no sujeito a sua razão. No inverso da imagem, para o sujeito o eu representa seu suporte material. Neste sentido, o eu, por ser "rede das identificaçōes alienantes" (Jorge, 1988: 73), tem o papel de estabilizar o lugar do sujeito. Através desse jogo de imagens, suspende-se - ainda que na ilusão constitutiva da ideologia (ou da fantasia (?)) - a disjunção eusujeito.

Deste processo, o personagem de Coração Satânico oferece um exemplo cabal, pois a sua afirmação de saber quem ele é aponta, de fato, para um outro eu (sujeito) que ele insiste em não (re)conhecer. A 
procura de que fora encarregado torna-se uma busca labirintica por sua própria identidade amnesiada (a amnésia é a falta, o ocultamento, efeito de alienaçāo causado pela ideologia).

Assim, no espaço intervalar eu-sujeito intervém um processo de dupla e simultânea açāo. Um processo que ao mesmo tempo em que estabelece a identificaçāo entre os dois actantes, oculta-se, gerando a ilusão de que identidade e sentido da relação eu/sujeito é um dado objetivo e evidente em si mesmo. O intervalo da relação entre um eu e um sujeito é preenchido pela ideologia. Resta, então, verificar alguns aspectos desse processo que transforma eus em sujeitos.

Althusser (1978 e 1980) compõe uma sistematização teórica sobre a relação entre sujeito e ideologia, a partir do marxismo e, tendo como foco de partida, uma reflexāo acerca da noção de ideologia. Para este autor, a ideologia é o que resulta do fato de os homens se representarem uma relação imaginária com suas condições reais de existência. Dai a ideologia apresentar-se como um sistema dominante de idéias, representaçōes, no qual todo ser humano encontra-se imerso e do qual depende. Isto acarreta, como conseqüência imediata, o fato de a ideologia ter uma existência material no interior de um sistema de práticas que, por sua vez, produz/reproduz as formaçōes ideológicas (Aparelhos Ideológicos de Estado). Dizer, então, ideologia, significa apontar ao "conjunto 'das formaçōes complexas de noçõesrepresentações-imagens, de uma lado, e de montagens-comportamentos-condutas-atitudes-gestos, de outro', que ele funciona 'como normas práticas que governam a atitude e a tomada de posiçāo concreta dos homens"' (Pisier-Kouchner, 1974: 267).

Esta concepção althusseriana de ideologia encontra em Debray (apud Maingueneau, 1993: 59) uma reflexão correlata que aponta a ideologia como instituindo processos organizacionais, mais do que estando limitada à esfera das representaçōes mentais. Segundo Debray "a ideologia, ao contrário do que se crê, não ocorre na esfera das idéias". A questão não é saber como uma idéia surge ou atua, mas de 
BORGES, Luiz C. Redemoinho às avessas ou um eu se auto-(re)clama sujeito.

saber qual o jogo entre pensamento, sistema de forças e a produção mesma desse pensamento. Ainda segundo Maingueneau (op, cit. : 59), para Debray "a ideologia ocupa-se simultaneamente da representação do mundo e da organização dos homens, tarefas que significam o direito e o avesso de uma mesma atividade". A partir deste conceito, pode-se concluir que todo corpo de idéias ou de doutrinas só se articula ao organizar, simultaneamente, uma instituição que o sustente e legitime. É deste modo que se articula tanto o pensamento cientifico quanto o senso comum.

Uma vez que a ideologia é a representação da relação imaginária do individuo com a sua realidade, e que esse processo envolve a totalidade do individuo, nāo há um lugar fora da ideologia. Pensar um fora da ideologia é estar, já e sempre, nos labirintos dos efeitos ideológicos.

Se "só há ideologia pelo e para o sujeito" (Althusser, 1980: 87) também é verdade que o sujeito é, por sua vez, efeito das formaçōes ideológicas. Deste modo, há, entre sujeito e ideologia, uma correlação, jogo de imagens, pois, se é a categoria sujeito que sintomatiza a ideologia, é esta que constitui não-sujeitos (individuos históricos) em sujeitos - a interpelaçāo do sujeito de ideologia. Isto significa dizer que só existe sujeito na e pela ideologia, pois o sujeito é efeito da interpelação. Por sua vez, é este processo de assujeitamento que produz a ilusão do sujeito sempre-já-lá. O sujeito é, portanto, uma categoria ideológica.

Este sujeito sempre-já-lá, efeito da imposição de uma forma-sujeito a nāo-sujeitos (o pré-construido), carrega uma identidade que o constitui como agente histórico. Cabe também aos processos ideológicos fornecer as evidências da identidade com que o sujeito se afirma. Ao dizer eu sou, é a estas evidências ideológicas que o sujeito se refere.

Os individuos, embora ativos como agentes de práticas sociais do processo histórico, não são livres. Atuam de acordo com as determinaçōes das formas de existência histórica das relaçōes sociais. $O$ agente se investe de uma forma-sujeito para poder agir historica- 
mente. Esta investidura (a interpelação) é feita pela formação ideológica dominante. Ao investirem-se em sujeitos, os individuos se assujeitam à ideologia, condição inegociável para que possam representarem-se autônomos. Althusser (1978: 67) considera que somente sob a determinação das relaçōes de produção e reprodução os agentes-sujeitos podem ser ativos na história. Dai falar em interpelação ideológica, a partir da qual o sujeito se constitui, e em forma-sujeito como a forma de existência histórica do individuo como o agente das práticas sociais.

Uma outra condiçāo para a constituição do sujeito, é que ele "só constrōi sua identidade na interação com o outro" (Brandão, 1993: 62). E esta interação constitutiva apresenta-se no discurso, pois o discurso, cenário em que intervêm um sujeito e um outro, institui-se como a maneira particular pela qual o sujeito se referencia ao outro. No espaço discursivo intervalar que faz interagir o eu e o outro, interpõem-se as condiçōes ditadas pela formação discursiva dominante, por sua vez determinada pelos processos de interpelação/identificaçāo no campo ideológico. A construçāo da identidade pelo sujeito, como efeito da atuação/apagamento dos processos ideológicos determinantes, se produz no preenchimento da forma-sujeito.

De acordo com Pêcheux (1988), a investidura do não-sujeito em sujeito, como parte da interpelação ideológica, desdobra-se em dois processos simultâneos ainda que distintos: a imposição e a dissimulação. No primeiro ocorre o assujeitamento, situando o individuo num lugar que lhe é destinado e num sentido que se compōe na rede de sentidos possiveis (o que ele é). Este é o momento da identificaçāo através da qual as evidências emergem - "eu sei quem eu sou"; "sou quem faço, decido". E, por ser evidente, em/por-si-mesmo, o sentido/identidade de que se reveste o sujeito, oculta-se-lhe o processo que o instituiu enquanto tal. Nesta instância age o segundo processo, o apagamento, a dissimulaçāo do seu assujeitamento. $\dot{E}$ atravês deste "esquecimento" que o sujeito imagina-se autônomo. dono dos seus sentidos. 
BORGES, Luiz C. Redemoinho às avessas ou um eu se auto-(re)clama sujeito.

A formação ideológica-discursiva que institui o sujeito, dotando-o de lugar e sentido, emerge como pré-construído e inscreve seus traços no discurso do próprio sujeito, dando-lhe a ilusão de autonomia e auto-evidência.

Já foi dito que a relação entre eu e sujeito é lúdica e de representação. Há entre eu e sujeito um jogo permanente de simulaçāo, no qual o eu-individuo projeta-se como sujeito-social, enquanto este último, por seu turno, transfigura-se em uma unidade dialética que, ao enunciar-se, constrói para si um EU. Tanto o eu quanto o sujeito referem-se a conjuntos de imagens (auto)projetadas na prática discursiva, mirando-se e refletindo-se simultânea e mutuamente. Se ao sujeito, entidade determinada pela coerção ideológica, corresponde uma projeção individualizada (o eu), materializando-se em realidade corporal. Este eu apresenta-se como entidade que homogeneiza/ hegemoniza o sujeito.

De fato, a materialidade do eu, a sua corporalidade, contém a deriva do sujeito nos limites de um termo-chave (o dizer: eu). Da perspectiva do eu (ao dizer: eu sei quem eu sou, por exemplo), a evocação de uma identidade imaginária remete a uma heterogeneidade que, por definição, manifesta-se como impossivel de ser compartimentada ou mesmo contida em seu fluxo. Ao dizer eu, de fato, a que remete a enunciação? Para onde aponta este eu que se projeta, em seu discurso, como unidade e como consciência?

Porque igualmente gerado por uma formação ideológica, o eu encontra-se alienado de sua própria heterogeneidade, pois, ao se manifestar (no corpo e no discurso) como uno, idêntico e cônscio, deixa escapar irreparavelmente a natureza de sua constituiçāo heterogênea. Se o sujeito sempre desemboca num eu, este, ao se anunciar, jamais se dá conta de estar apontando para uma diversidade constitutiva.

Neste jogo de simulação/dissimulação que materializa uma unidade/identidade dialética, eu e sujeito são gestos do mesmo movimento. Como uma banda de moebius, eles se constituem mutua- 
Rev. ANPOLL, n. 8, p. 103-129, jan./jun. 2000

mente, num único tempo. Conquanto heterogêneos, nāo há entre eu e sujeito espaço/tempo para descontinuidade.

\section{Sujeitos de algures a nenhures}

Porque em Althusser e em Pêcheux há recorrentes referências à psicanálise, insistindo no fato de que, enquanto estruturas teóricas, ideologia e inconsciente apresentarem-se como conceitos teóricos de mesmo nivel, é importante, ainda que correndo riscos de reducionismo de ambas as correntes, comentar alguns pontos comuns entre as duas teorias.

Como ponto de partida, é mister reconhecer que os objetos teóricos ideologia e inconsciente guardam entre si certas similaridades, considerando que ambos estão no mesmo nivel, nas duas teorias, como determinantes, em primeira e última instância, do sujeito. Contudo, ainda que se considere que ideologia e inconsciente representam para o marxismo e para a psicanálise, respectivamente, centros de importantes reflexões teóricas, isso nāo significa que haja um recobrimento desses conceitos, ou que um possa ser reduzido ao outro. Para o marxismo a ideologia não representa um em-si. Ao contrário, ela é parte do processo histórico-social das condiçōes e relaçōes de produção/reproduçāo. Tal não parece ser o status teórico do inconsciente para a psicanálise.

Em seu artigo a ação da estrutura, Miller afirma (p. 82) que "a Psicanálise, assim como o marxismo, dá o principio de uma organização nova do campo conceitual". Mais adiante, falando mais uma vez sobre a relação entre o discurso marxista e o freudiano, como discursos da sobredeterminação e, como possiveis de constituir um discurso teórico único (desde que fossem operadas transformaçōes regulares), Miller pōe a descoberto a condiçāo pela qual marxismo e psicanálise poderiam confluir: "porque o primeiro está atualmente liberado por Louis Althusser da hipoteca que fazia pesar sobre ele a 
BORGES, Luiz C. Redemoinho às avessas ou um eu se auto-(re)clama sujeito.

concepçāo da sociedade como sujeito histórico, como o segundo o foi por Jacques Lacan da interpretaçāo do individuo como sujeito psicológico" (p. 95).

Em primeiro lugar, parece não pairar dúvidas quanto ao fato de que, a partir o marxismo e da psicanálise, o campo conceitual reorganiza-se, deslocando-se de um eixo empírico-positivista, a partir de um novo ponto de vista epistemológico que se descola do real da história para enveredar por um campo exigentemente teórico. É neste contexto que o marxismo e a psicanálise, surgidos no mesmo horizonte intelectual, partilham da mesma força revolucionária, como deflagradores de um novo modo de pensar-(transformar?)-interpretar o mundo.

A formulaçāo teórica do inconsciente, em Freud, implica necessariamente não apenas uma reformulação conceitual, como também a inauguração de um novo ponto de vista teórico-metodológico. Ao colocar o inconsciente como o centro determinador deste novo horizonte conceitual, coloca-se igualmente em questão conceitos e categorias epistemológicas até então razoavelmente estabilizados: a questão do desejo, do sujeito, da identidade, do real, por exemplo.

O marxismo também inaugura um novo horizonte conceitual, ao colocar como eixo as condições materiais da existência enquanto resultantes de um processo histórico e social: as formaçōes econômico-sociais. Ao constatar que as visōes de mundo, as formas de organizaçāo social, as ideologias definem-se como processos históricos constituidos sobre a base material das condiçōes de existência, o marxismo também afirma que elas expressam um modo particular de ser/ver de uma dada historicidade. Ou, para usar uma expressāo gramsciana, as visōes de mundo dominantes, conformadoras do horizonte intelectual (Löwy, 1988), estão relacionadas a um bloco histórico dominante.

Contrariamente à afirmação de Miller, para quem poder-se-ia constituir um discurso teórico único marxista-psicanalitico, encontrase na configuraçāo teórica dessas disciplinas, ao que tudo indica, pon- 
tos de disjunção que provocariam verdadeira disfunçāo constitutiva nesse tipo de discurso. Isto porque deve-se levar em consideração que cada uma dessas disciplinas ancora sua prática teórica em categorias téorico-filosóficas que não são mutuamente reversiveis. O conceito de inconsciente, diferentemente do conceito de ideologia, não parece derivar das condições materiais da existência e, como tal, das condições de produçāo e das relaçōes sociais dai determinadas, de sorte que ideologia e inconsciente, ainda que ligados pela linguagem, apresentam materialidades e historicidades de diferentes ordens.

Se, de uma certa forma, o inconsciente psicanalitico encontra sua contraparte no conceito marxista de ideologia, deve-se verificar de que modo, marxismo e psicanálise, concebem uma teoria do sujeito. Grosso modo, a teoria marxista de sujeito, como já ficou evidente, parte da noçāo de ideologia, ao passo que é a partir do inconsciente que a psicanálise deriva a sua noção de sujeito. Desse modo, a concepção do objeto teórico sujeito constitui um desses pontos nodais que tornam marxismo e psicanálise, a despeito de suas mútuas aproximaçōes, em permanente queda livre e, por onde, a hipótese de discurso único proposto por Miller escapa.

Para o marxismo, o sujeito só pode ser concebido como socialhistoricamente determinado, uma vez que a sua materialidade reflete/refrata as condições materiais da existência (cf. a noçāo althusseriana de sujeito assujeitado). Neste sentido, o sujeito resulta dos processos de reproduçāo e transformaçāo das relações de produção, mediante atribuição de posição derivada de uma dada formação histórico-social. Para a psicanálise, o sujeito do desejo inconsciente é um sujeito desde-sempre-dado, universal, derivado de uma estrutura em si mesma estruturada/estruturante: "é a partir da estrutura que é preciso engajar a teoria do sujeito (...). A ordem que, da estrutura vai ao sujeito, è aqui essencial preservar" (Miller: 87).

É, pois, em seus principios fundadores que a prática teórica marxista e a psicanalitica discrepam. Contrapōem-se duas materialidades: de um lado o inconsciente psicanalitico e, de outro, a ideolo- 
BORGES, Luiz C. Redemoinho às avessas ou um eu se auto-(re)clama sujeito.

gia marxista. Pode-se, fazendo um correlato com certas posiçōes da teoria psicanalitica, contrapor duas noçōes de materialidade: de um lado o inconsciente psicanalítico e, de outro, a ideologia marxista. A origem/causa/efeito da materialidade da ideologia, conforme concebida pelo marxismo, encontra-se nas condiçōes materiais da existência. Isto é, é o processo social e histórico que determina tanto a ideologia quanto a consciência. Parece ser justo concluir que, se visto a partir do marxismo, o inconsciente também refletiria essa historicidade. Para a psicanálise, ao contrário, o inconsciente é omni-histórico: uma estrutura, um sempre-já-aí estruturante do individuo.

O sujeito (do (desejo) inconsciente) configura-se como um sujeito omni-histórico (é na história individual que ele se redige), ao passo que o sujeito, na teoria marxista, define-se a partir da noção de ideologia. O que há de comum entre o sujeito do inconsciente e o da ideologia é que ambos sāo efeitos de uma representação (para a psicanálise, efeito da linguagem, enquanto estrutura do inconsciente; para o marxismo, efeito da ideologia), e que em ambos opera-se uma alienação constitutiva que faz com que o sujeito acredite-se ser a causa/efeito de si mesmo. Para usar os termos de Miller (p. 90): “...uma alienaçāo é essencial ao sujeito pelo fato de que ele nāo se efetua como agente senão no imaginário. (...). Ator, ele é diretor no seu fantasma". Para o marxismo, entretanto, a alienação não se apresenta como uma condição a-histórica. Ao contrário, ela resulta de um processo de dissimulação da ideologia.

Deste modo, uma teoria marxista do sujeito deve partir das "condiçōes ideológicas da reprodução/transformaçāo das relações de produçāo" (Pêcheux, 1988: 180). Assim concebido, o sujeito da ideologia inscreve-se na materialidade histórica e social como efeito das formaçōes ideológicas atuantes, por sua vez, efeito/causa de um bloco hegemônico.

Assim sendo, a despeito de haver pontos de convergência teórica entre marxismo e psicanálise (por exemplo, a alienação constitutiva do sujeito, a partir da ilusão estruturante de efeito ideológico, pela 
qual ele se põe na posiçāo de senhor de seu discurso), a prática teórica marxista e a psicanalitica constróem discursos que não são mutuamente conciliáveis. Para que pudesse haver o livre trânsito entre eles, preconizado por Miller, seria necessário que ambos passassem por transformaçōes que os liberassem de alguns dos pontos cruciais e fundadores que os constituem como método de inquirir/compreender o mundo.

\begin{abstract}
Based on the theoretical pressupositions of the Discourse Analysis, the main goal of this paper is to establish a discussion concerning the crucial notion of discoursive subject, as it is understood as one of the cornerstones of a historical-ideological formation, according to a marxist understanding of discourse. Therefore, to comprehend the subject's discoursive functioning, as well as its structuring and constitutivity one needs to aprehend it following the axis of recognition/ identification, cunter-identification, alterity. In order to better locate this discussion, a analytical and methodogical relation between the subject of the unconscious, as considered by the Psychoanalysis and the subject of the discourse is drawn. Through this kind of procedure, it become possible to establish some converging an some divergent points between the psychoanalytic and the marxist theoretical perspectives on what concerns the discoursive constitution and functioning of the notion of subject.
\end{abstract}

KEY-WORDS: Subject; Ideology: Alienation; Identification.

\title{
Bibliografia
}

ALTHUSSER, L. (1978) Posiçōes - 1. Rio de Janeiro: Graal. (1980) Posiçōes - 2. Rio de Janeiro: Graal.

BADIOU, A. (1994) Para uma nova teoria do sujeito. Rio de Janeiro: RelumeDumará.

BRANDĀO, H. H. N. (1993) Introdução à análise do discurso. Campinas: Ed. Unicamp. 
BORGES, Luiz C. Redemoinho às avessas ou um eu se auto-(re)clama sujeito.

CODO, W. (1986) O que é alienaçāo. São Paulo: Nova Cultural/Brasiliense. (Primeiros Passos, 88).

HAROCHE, C. (1992) Fazer dizer, querer dizer. São Paulo: Hucitec.

HENRY, P. (1990) Os fundamentos teóricos da "Análise Automática do Discurso" de Michel Pêcheux (1969). In: GADET, F., T. HAK (orgs. ) Por uma análise automática do discurso. Uma introduçāo à obra de Michel Pēcheux. Campinas: Ed. da UNICAMP. p. 13-38.

. (1992) A ferramenta imperfeita. Lingua, sujeito e discurso. Campinas: Ed. Unicamp.

HERBERT, T. (1995 [1967]). Observaçōes para uma teoria geral das ideologias. RUA, n. 1:63-89.

JORGE, M. A. C. (1988) Sexo e discurso em Freud e Lacan. Rio de Janeiro: Jorge Zahar.

LAPLANCHE, J., J.-B. PONTALIS (1990) Fantasia Originária, fantasias das origens, origens da fantasia. Rio de Janeiro: Jorge Zahar.

LEITE, N. (1994) Psicanálise e análise do discurso: o acontecimento na estrutura. Rio de Janeiro: Campo Semântico.

LÖWY, M. (1987) As aventuras de Karl Marx contra o Barāo de Münchhausen: marxismo e positivismo na sociologia do conhecimento. São Paulo: Busca Vida.

MAINGUENEAU, D. (1993) Novas tendēncias em análise do discurso. Campinas: Pontes.

MILLER, J.-A. A ação da estrutura. Tempo Brasileiro. Epistemologia, n. 28:8295.

ORLANDI, E. P. (1987) A linguagem e seu funcionamento. As formas do discurso. Campinas: Pontes.

- (1990) Terra à vista. Discurso do confronto: velho e novo mulndo. Sāo Paulo: Cortez; Campinas: Ed. Unicamp.

. (1992) As formas do silêncio. No movimento dos sentidos. Campinas: Ed. Unicamp.

(1994) O lugar das sistematicidades lingüisticas na Análise do Discurso. Rev. D. E. L. T. A., v. 10, n. 2: 295-307.

PÊCHEUX, M. (1988) Semântica e discurso. Uma afưrmação crítica à afirmação do óbvio. Campinas: Ed. Unicamp.

PÊCHEUX, M., C. FUCHS (1990). A propósito da análise automática do discurso: atualizaçāo e perspectivas (1975). In: GADET, F., T. HAK (orgs.) 
Rev. ANPOLL, n. 8, p. 103-129, jan./jun. 2000

Por uma análise automática do discurso. Uma introdução à obra de Michel Pêcheux. Campinas: Ed. da UNICAMP. p. 163-252.

PISIER-KOUCHNER, E. (1974). Os marxismos. In: CHÃTELET, F. (1974) História da Filosofia, idéias, doutrinas. 8. O Século XX. Rio de Janeiro: Zahar. p. 238-270.

POSSENTI. S. (1990) Perguntas em torno de quatro temas. Cadernos de Estudos Lingüisticos, n. 19: 97-115.

SAFOUAN, M. (1970) Estruturalismo e Psicanálise. São Paulo: Cultrix. 